\title{
Journal of Operational Meteorology Article \\ Examination of a Winter Storm Using a Micro Rain Radar and AMDAR Aircraft Soundings
}

\author{
BARRETT L. SMITH and JONATHAN L. BLAES
}

National Weather Service, Raleigh, North Carolina

(Manuscript received 26 April 2015; review completed 23 September 2015)

\begin{abstract}
Winter storms along the United States East Coast are often high-impact events with complex forecasts. Forecasts can be particularly difficult in the lee of the Appalachian Mountains, where terrain-induced coldair damming (CAD) creates an environment suitable for multiple and rapidly changing precipitation types. A winter storm that impacted central North Carolina on 18 January 2007-and featured a common CAD setup-provided the National Weather Service Forecast Office in Raleigh, North Carolina, an opportunity to use two nontraditional observing systems during a rapidly changing precipitation-type event. This study details how aircraft soundings and a vertically pointing micro rain radar (MRR) were utilized to monitor changing precipitation types and improve the 3-6-h forecast. Aircraft observations from the RaleighDurham International Airport were available at various times during the event, allowing forecasters to monitor changes in the thermal profile of the environment, and more specifically, the strength and depth of a warm (melting) layer centered around $1000 \mathrm{~m}$. In addition, the MRR provided frequent observations of the melting layer height and evolution, providing useful information to more accurately forecast the onset of mixed precipitation types, a changeover to all snow, and eventually, a change to all rain. These observational datasets also were used to verify Rapid Update Cycle forecasts. The results of this event demonstrate the utility of these nontraditional datasets during critical decision making and high-impact events.
\end{abstract}

\section{Introduction}

The critical and often widespread impacts of United States East Coast winter storms are well documented by Kocin and Uccellini (2004), and precipitationtype (herein referred to as p-type) forecasting long has been a difficult task for weather forecasters in this region. During any given event, as many as four different p-types can be observed east of the Appalachians over the Carolina and Virginia Piedmont. This is a result of cold-air damming (CAD, Bell and Bosart 1988; Bailey et al. 2003), where cold air becomes trapped along the eastern slopes of the Appalachians and can create sharply contrasting air masses across the region (Keeter et al. 1995). Stark differences between the CAD air mass and much warmer air masses modified by the Gulf Stream off the Southeast Coast influence narrow transition lines between liquid and frozen precipitation. To further complicate matters, the transition zone between p-types is often migratory and influenced by horizontal temperature advection and latent heat release through diabatic processes (Brennan and Lackmann 2005). The location and movement of such transition zones can result in significant differences between a cold rain with little societal impact, and frozen precipitation (sleet, freezing rain, and snow) with a tremendous impact just $1-3 \mathrm{~km}$ away.

The current observation network of upper-air soundings and surface observations does not always resolve spatial and temporal variations in p-type transition zones. For example, radiosonde releases in North Carolina occur only at Greensboro (KGSO) and Morehead City (KMHX; Fig. 1). These sites are $>300 \mathrm{~km}$ apart and often a substantial distance on either side of the p-type transition zone, which climatologically lies roughly north-south through a portion of North Carolina (Keeter et al. 1995). In addition, the vertical thermal profile can evolve rapidly during periods of changing p-types (often only $1-3 \mathrm{~h}$ ) owing to factors such as horizontal thermal advection or latent heating effects (Kain et al. 2000). During this time, multiple ptypes often are observed as well (Maglaras et al. 1995; Hux et al. 2001). The frequency of observations in the 
standard surface observation network is often insufficient to efficiently resolve fast-changing surface temperature and precipitation types. Such gaps in both upper-air and surface observations necessitate an alternative way of viewing the atmosphere vertically with high spatial and temporal frequency, in order to observe and better anticipate rapidly changing p-types. Numerical weather prediction models can struggle to accurately predict temperature and other fields critical in winter storm forecasting (Lackmann et al. 2002), particularly when it comes to the role of deep moist convection and microphysics associated with the evolution of winter storm systems (Wang and Seaman 1997; Zhang et al. 2003), which provides an additional impetus for forecasters to utilize all available observational tools to thoroughly evaluate model guidance.

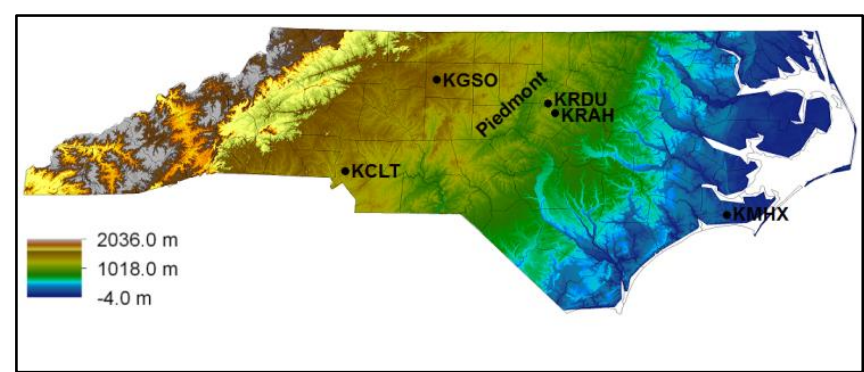

Figure 1. Topographic map of North Carolina with relevant surface (black dots), upper-air (KGSO and KMHX), and National Weather Service (NWS; KRAH) sites labeled (as discussed in the text). The "Piedmont" is a plateau region located in the eastern United States between the Atlantic Coastal Plain and the main Appalachian Mountains, stretching from New Jersey in the north to central Alabama in the south. Click image for an external version; this applies to all figures hereafter.

Forecasts of these p-types often pique public interest several days ahead of the event and can have a significant impact on decision making leading up to and during the event. In the southeastern United States, where frozen precipitation typically occurs $<5 \mathrm{yr}^{-1}$ (Gay and Davis 1993), even the lightest accumulation of snow or ice is cause for concern. For example, a brief and small-scale $2.5-\mathrm{cm}$ (1 in) snow event in the Raleigh-Durham area on 19 January 2005 led to national headlines as traffic conditions quickly deteriorated and gridlock ensued. In 2009 alone, winter precipitation cost the North Carolina Department of Transportation \$65 million (North Carolina Department of Transportation 2009, personal communication). More complicated events-such as a recent storm on 16-17 February 2015-involve multiple ptypes over a much larger area, creating significant forecast difficulties in both time and space (Fig. 2).

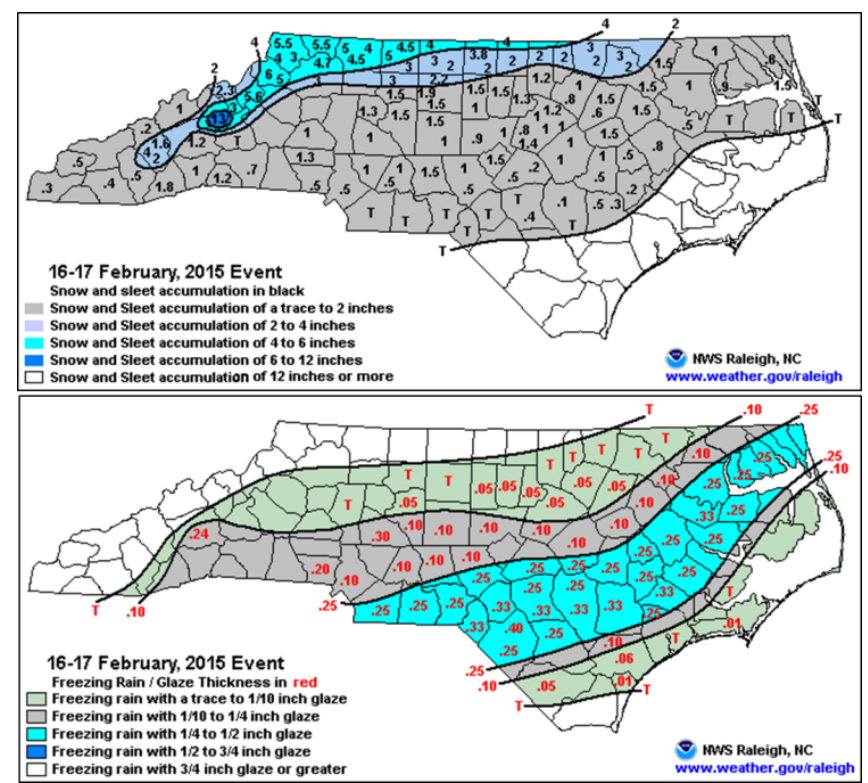

Figure 2. Snow and sleet accumulations (in; multiply by 2.54 for $\mathrm{cm})$ for the 16-17 January 2015 winter weather event. Observations are from NWS cooperative observers and public reports.

Improved forecasts of the onset and evolution of mixed precipitation events would be a great benefit to the public and decision makers.

The primary objective of this paper is to describe the successful use of two additional forms of upper-air observations - namely, a vertically pointing micro rain radar (MRR; Peters et al. 2002) and soundings from commercial aircraft - in forecast operations. Section 2 gives background for the MRR and aircraft soundings. The 18 January 2007 winter weather event is described in section 3; improvements to the forecast and awareness of mesoscale processes from added observations are discussed in section 4; and conclusions are presented in section 5 .

\section{Background}

Even though additional datasets undoubtedly were used during the forecast process, the purpose of this study is to focus on the MRR and aircraft soundings. The very recent additions of dual-polarization radar data (Kumjian 2013) and new Weather Surveillance Radar-1988 Doppler (WSR-88D, Crum and Alberty 1993) volume-coverage pattern scanning strategiessuch as the Automated Volume Scan Evaluation and Termination (AVSET) and the Supplemental Adaptive Intra-Volume Low-Level Scan (SAILS, Daniel et al. 2014) — offer much needed additional data and improved scanning strategies, but are not within the scope of this study. 


\section{a. Aircraft Meteorological Data Relay soundings}

The process of collecting weather reports via aircraft began in the early 20th century, when World War I pilots began recording in-flight conditions to be processed after landing. Moninger et al. (2003) provided a useful summary of the evolution of aircraft soundings, from the early military-based observations that influenced the development of the current radiosonde network, to the contemporary data that are transmitted in near real-time across the world. The term AMDAR (Aircraft Meteorological Data Relay) encompasses the many different aircraft sounding datasets in use, including the Aircraft Communications Addressing and Reporting System, Tropospheric Airborne Meteorological Data Reporting, Meteorological Data Collection and Reporting System, Network of European Meteorological Services Aircraft Meteorological Data Relay, and Canadian AMDAR.

Aircraft observations are dependent on flight path and altitude, with the bulk of aircraft observations taking place while cruising at high altitudes (between 7500 and $14000 \mathrm{~m}$ ), although some aircraft cruise at lower altitudes and make more frequent ascents/ descents (Moninger et al. 2003). However, the observations during ascent and descent often are of more direct interest to forecasters. These observations that are taken in the lower portion of the troposphere are especially important in winter when low-level thermal and moisture characteristics can have a tremendous impact on the eventual surface p-type. National Weather Service (NWS) Forecast Offices (NWSFOs) have been using AMDAR data since the early 1990s (Moninger et al. 2003), and support from the National Oceanic and Atmospheric Administration (NOAA) to provide AMDAR data to forecasters has spurred further interest in the data. An analysis of aircraft soundings available from the Raleigh-Durham International Airport (KRDU) in North Carolina during a 12-mo period from 1 June 2008 through 31 May 2009 is shown in Fig. 3. On average, there are 1-3 soundings available during peak air traffic periods, which typically occur at 0600-1000 LST and 1800-2200 LST. Prior case studies at NWSFO Raleigh, North Carolina, have shown that soundings from these periods can be quite useful in forecasting p-type, evaluating the potential for near-term severe convection, and preparing aviation forecasts.

There are several recognized limitations with AMDAR data. Whereas the data may be available during some events, they can just as often be unavail- able owing to flight schedules or weather interruptions of air traffic. Moisture profiles frequently are not available, although there has been some effort to increase the number of aircraft carrying moisture sensors (Moninger et al. 2010). Because the observations are taken by aircraft following air traffic routes at relatively high speeds, forecasters need to note that the location being sampled is not directly over the airport or a function of the wind vector as with radiosondes, but instead may follow a long and semi-irregular course toward or away from the airport. Finally, with some AMDAR networks, the observations are not recorded at a true height above ground level, but instead are logged based on a standard atmospheric pressure, which inherently introduces uncertainty or error in interpreting the data. However, forecasters are trained to recognize these limitations and apply some restraint when using the data quantitatively.

\section{b. Vertically pointing micro rain radar}

Conventional weather radars have been in use since the mid-20th century and have undergone numerous changes and upgrades, including the development of Doppler capabilities, dual-polarization technology, and growth of the WSR-88D network. Even with 158 deployed oper-ational WSR-88Ds across the United States, limitations of radar coverage remain, including scan time and decreasing low-level detection with increasing distance from the radar.

The vertically pointing radar is a nontraditional system that can offer valuable assistance with these limitations of the WSR-88D network via a unique vertical perspective and a high degree of temporal resolution. Vertically pointing radar systems have been used extensively over the past three decades during field research projects, but their use by operational forecasters has been very limited. Increased temporal and vertical resolution obtained by continuously scanning in the vertical has been useful in numerous research areas, including dropsize distributions (Yuter and Houze 2003; Peters et al. 2005; Martner et al. 2008), cloud characteristics (Rauber et al. 1986), wave structure (Martner and Ralph 1993), convection (Martner 1997), and various other hydrometeorological studies. The use of vertically pointing radars has been limited across the eastern United States, with instruments principally located in North Carolina and New York (Yuter et al. 2008). The MRR was tested as part of the operational forecast process during the winter of 


\begin{tabular}{|l|l|l|l|l|l|l|l|l|l|l|l|l|l|l|l|l|l|l|l|l|l|l|l|l|}
\hline \multicolumn{1}{|r|}{ LST } & 01 & 02 & 03 & 04 & 05 & 06 & 07 & 08 & 09 & 10 & 11 & 12 & 13 & 14 & 15 & 16 & 17 & 18 & 19 & 20 & 21 & 22 & 23 & 00 \\
\hline UTC & 06 & 07 & 08 & 09 & 10 & 11 & 12 & 13 & 14 & 15 & 16 & 17 & 18 & 19 & 20 & 21 & 22 & 23 & 00 & 01 & 02 & 03 & 04 & 05 \\
\hline Monday & 0.0 & 0.0 & 0.0 & 0.0 & 0.0 & 1.3 & 1.1 & 0.4 & 0.9 & 2.1 & 0.4 & 0.9 & 1.5 & 0.4 & 0.8 & 0.5 & 1.4 & 2.4 & 2.0 & 1.4 & 0.3 & 0.8 & 0.3 & 0.0 \\
\hline Tuesday & 0.0 & 0.0 & 0.1 & 0.7 & 0.7 & 2.4 & 1.7 & 0.5 & 1.1 & 2.0 & 0.8 & 0.8 & 1.5 & 0.5 & 0.6 & 0.4 & 1.5 & 3.2 & 2.0 & 1.2 & 0.4 & 3.1 & 0.3 & 0.0 \\
\hline Wednesday & 0.0 & 0.0 & 0.1 & 0.7 & 0.9 & 2.1 & 1.9 & 0.7 & 1.0 & 1.6 & 0.7 & 0.8 & 1.6 & 0.3 & 0.8 & 0.5 & 1.4 & 3.1 & 2.0 & 1.5 & 0.4 & 3.0 & 0.4 & 0.0 \\
\hline Thursday & 0.0 & 0.0 & 0.3 & 0.6 & 0.9 & 2.3 & 1.8 & 0.5 & 1.0 & 1.8 & 0.7 & 1.2 & 1.4 & 0.3 & 0.7 & 0.5 & 1.3 & 2.8 & 2.0 & 1.3 & 0.3 & 3.0 & 0.3 & 0.1 \\
\hline Friday & 0.0 & 0.0 & 0.1 & 0.7 & 0.9 & 2.3 & 1.6 & 0.5 & 1.0 & 2.4 & 0.6 & 1.0 & 1.8 & 0.4 & 0.9 & 0.4 & 1.4 & 3.1 & 2.0 & 1.5 & 0.5 & 3.1 & 0.2 & 0.0 \\
\hline Saturday & 0.0 & 0.0 & 0.0 & 0.0 & 0.1 & 2.2 & 1.8 & 0.3 & 0.6 & 1.9 & 0.5 & 1.0 & 1.4 & 1.2 & 0.6 & 0.2 & 0.7 & 1.2 & 1.8 & 1.7 & 0.3 & 1.6 & 0.3 & 0.1 \\
\hline Sunday & 0.0 & 0.0 & 0.0 & 0.0 & 0.0 & 0.7 & 1.2 & 0.3 & 0.7 & 1.4 & 0.8 & 0.6 & 1.5 & 0.7 & 0.7 & 0.5 & 1.3 & 2.9 & 1.5 & 0.5 & 0.2 & 0.1 & 0.0 & 0.0 \\
\hline
\end{tabular}

Figure 3. Average hourly AMDAR soundings at Raleigh-Durham International Airport (KRDU) available to NWSFO forecasters via their workstation (Local Standard Time on $x$ axis). Color coding is related to the frequency of soundings (e.g., red for $\geq 2.0$ ).

2007 at the Raleigh, North Carolina, NWSFO (KRAH in Fig. 1). In collaboration with North Carolina State University, a vertically pointing MRR (Ku-band) was placed on the roof of the NWSFO building with realtime data made available to forecasters. Table 1 provides the hardware and processing specifications of the MRR. Several winter precipitation events occurred while the MRR was deployed, and Yuter et al. (2008) described some of the relationships between MRR data and environmental conditions over the radar. As discussed previously, mixed p-type events often are highimpact events during the cold season in central North Carolina. The depth and magnitude of the layers of warm air aloft can vary widely in both time and space, sometimes completely eroding and reemerging in $<1$ h. One of the more significant features of the MRR is the ability to visualize the melting layer and how precipitation and/or thermal advection modify the atmosphere by viewing the vertical reflectivity and Doppler velocity of hydrometeors aloft. Identification of the type of hydrometeor aloft can improve forecasts of $\mathrm{p}$ type at the surface. By monitoring the hydrometeor type, forecasters can identify not only the onset of precipitation, but also changes in the thermal pattern, which also can increase the lead time of predicting $\mathrm{p}$ type changes at the surface and allow forecasters to compare model forecasts with observations.

Vertically pointing radars are not as common as traditional scanning radars and many forecasters may not be as familiar with how the output is typically displayed. Therefore, it is necessary to briefly describe how data from the MRR in this paper can be interpreted, using Fig. 4 as an example. Yuter et al. (2008) provide further insight into using the MRR for precipitation detection and forecasting. In Fig. 4, both reflectivity and Doppler velocity are plotted on a time versus height graph, with time on the abscissa ( $x$ axis) and height on the ordinate ( $y$ axis). Reflectivity values are
Table 1. Processing specifications of the micro rain radar (MRR) hardware used during the 18 January 2007 winter storm.

\begin{tabular}{|l|l|}
\hline Hardware & Processing specifications \\
\hline $\begin{array}{l}\text { Transmit } \\
\text { Frequency }\end{array}$ & $24.1 \mathrm{GHz}(1.24-\mathrm{cm}$ wavelength $)$ \\
\hline Transmit Power & $50 \mathrm{~mW}$ \\
\hline Beam width & $2^{\circ}$ \\
\hline Height resolution & $150 \mathrm{~m}$ \\
\hline Averaging time & $30 \mathrm{~s}$ \\
\hline $\begin{array}{l}\text { Measured } \\
\text { variables }\end{array}$ & $\begin{array}{l}\text { Height, spectra, drop spectra, radar reflectivity, } \\
\text { rain rate, and fall velocity. }\end{array}$ \\
\hline Dimensions & $0.6 \mathrm{~m} \times 0.6 \mathrm{~m} \times 0.6 \mathrm{~m}$ \\
\hline
\end{tabular}

plotted in $\mathrm{dBZ}$ and display typical values between 5 and $40 \mathrm{dBZ}$, although attenuation often is a problem in heavy rain and thunderstorms when the reflectivity is much higher. Attenuation is less of an issue during the cool season, when the melting layer will appear as a layer of high reflectivity owing to ice becoming watercoated during the melting phase. This can be seen in Fig. 4 where reflectivity values quickly change from $<20 \mathrm{dBZ}$ to $>30 \mathrm{dBZ}$ around $1000 \mathrm{~m}$. Similarly, the Doppler velocity increases at the melting level, and the higher values extend to the ground because of rain or sleet falling faster than the snow above. When all snow is falling (prior to 1200 UTC in Fig. 4), both the reflectivity and Doppler velocity will exhibit a slope downward and forward in time owing to the amount of time it takes for the snow to reach the ground.

\section{Case summary}

The following is a summary of the 18 January 2007 winter storm that impacted central North Carolina. In addition to the AMDAR and MRR data, which are the focus of this study, North American Regional Reanalysis (NARR; Mesinger et al. 2006) data and Rapid Update Cycle (RUC) model output (Benjamin et 


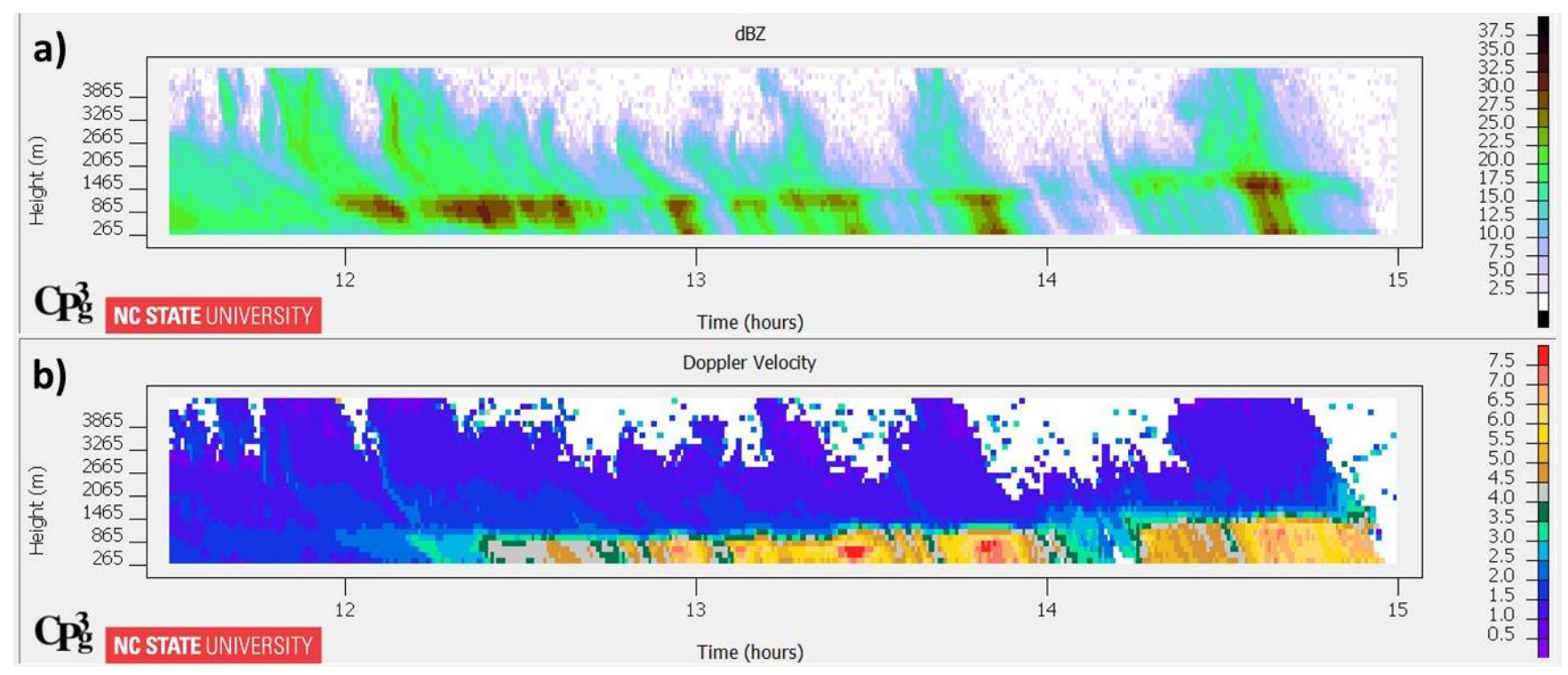

Figure 4. An example plot of data from an MRR showing a) reflectivity (dBZ) and b) Doppler velocity ( $\mathrm{m} \mathrm{s}^{-1}$ ). Time is in UTC.

al. 2004) are used to briefly describe the evolution of the event.

Most winter storms are characterized by several inches of accumulating ice and snow, with the definition of a winter storm typically varying by region. The snow accumulation amounts over central North Carolina on 18 January 2007 did not meet the local criteria of $7.6 \mathrm{~cm}$ (3 in) in $12 \mathrm{~h}$ (Fig. 5). In fact, this storm did not produce local warning criteria of sleet $(1.3 \mathrm{~cm}$ or $0.5 \mathrm{in})$ or freezing rain $(0.6 \mathrm{~cm}$ or $0.25 \mathrm{in})$ either. Instead, only $2.5-5.1 \mathrm{~cm}(1-2$ in) of snow and sleet fell over a rather small area. However, the snow and sleet fell during the morning rush-hour commute over a metropolitan area, which magnified the impact. Moreover, rapidly changing p-types complicated the nearterm forecast. Also, the storm provided a case of rapidly transitioning p-types directly over the MRR unit and during a relative peak of local air traffic, which offers an opportunity to examine the two additional datasets.

During the evening of 17 January 2007, a strong upper-level jet evolved between a broad ridge over the Gulf of Mexico and a transitory large-scale wave over the upper Midwest (Fig. 6a). Large-scale forcing for ascent during this event was driven by this jet and the associated secondary circulations, as differential positive vorticity advection was relatively weak (Fig. 6b). Beneath short-wave ridging aloft, a strong 1042-hPa surface high pressure was centered over New England (Fig. 6c), with a surface pressure ridge extending down the eastern side of the Appalachian Mountains into northern Georgia and a relatively dry air mass over the Carolinas (Fig. 6d). This pattern is consistent

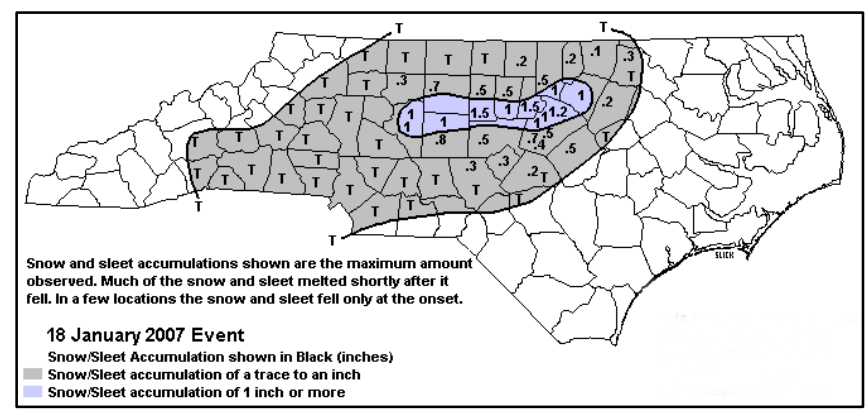

Figure 5. Snow and sleet accumulations for the 18 January 2007 winter weather event. Observations are from NWS cooperative observers and public reports.

with a classic CAD configuration (Bailey et al. 2003). The upper-level pattern was progressive as the shortwave ridge axis shifted east during the morning of 18 January (Figs. 7a-b). The surface high center moved off the New England Coast, while a weak inverted surface trough developed off the Carolina Coast (Fig. 7c), and deep moisture increased across the southeastern United States (Fig. 7d). A progressive pattern with the surface high center located off the New England Coast is typical for a hybrid CAD (Bailey et al. 2003) event where a decrease in cold advection is compensated by diabatic processes. The 0000 UTC 18 January 2007 sounding from KGSO showed a cold and dry air mass lingering near the surface (Fig. 8). Precipitation falling into this cold and dry air mass would produce evaporational cooling at the surface and reinforce the development of CAD. Precipitation generated by the intense subtropical jet moved quickly across the southeastern United States during the early evening (Fig. 

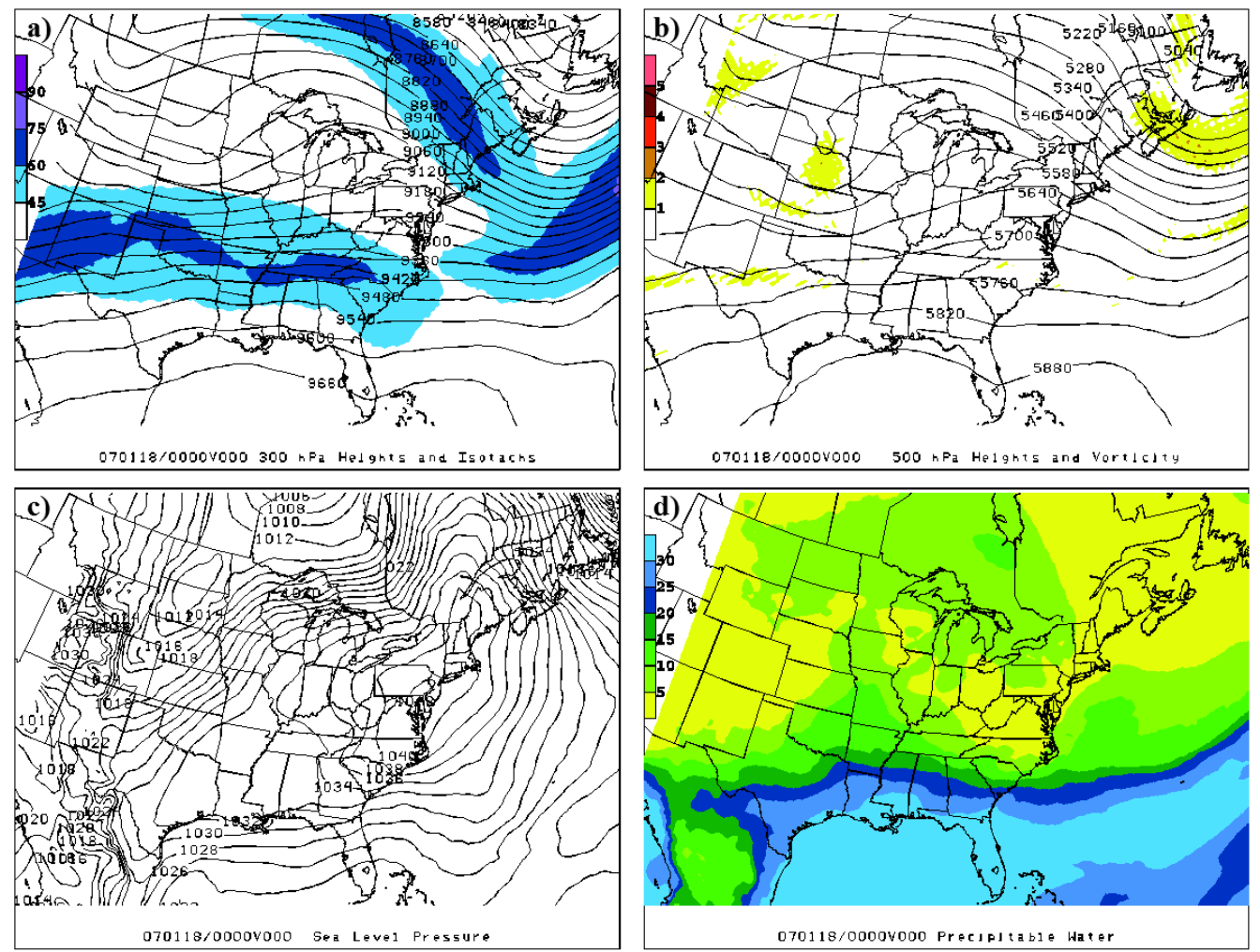

Figure 6. NARR plots for 0000 UTC 18 January 2007 showing a) 300-hPa geopotential height (m) and wind isotachs $\left(\mathrm{m} \mathrm{s}^{-1}\right)$, b) 500-hPa geopotential height $(\mathrm{m})$ and relative vorticity $\left(10^{-4} \mathrm{~s}^{-1}\right)$, c) sea-level pressure $(\mathrm{hPa})$, and $\mathrm{d})$ precipitable water $(\mathrm{mm})$.
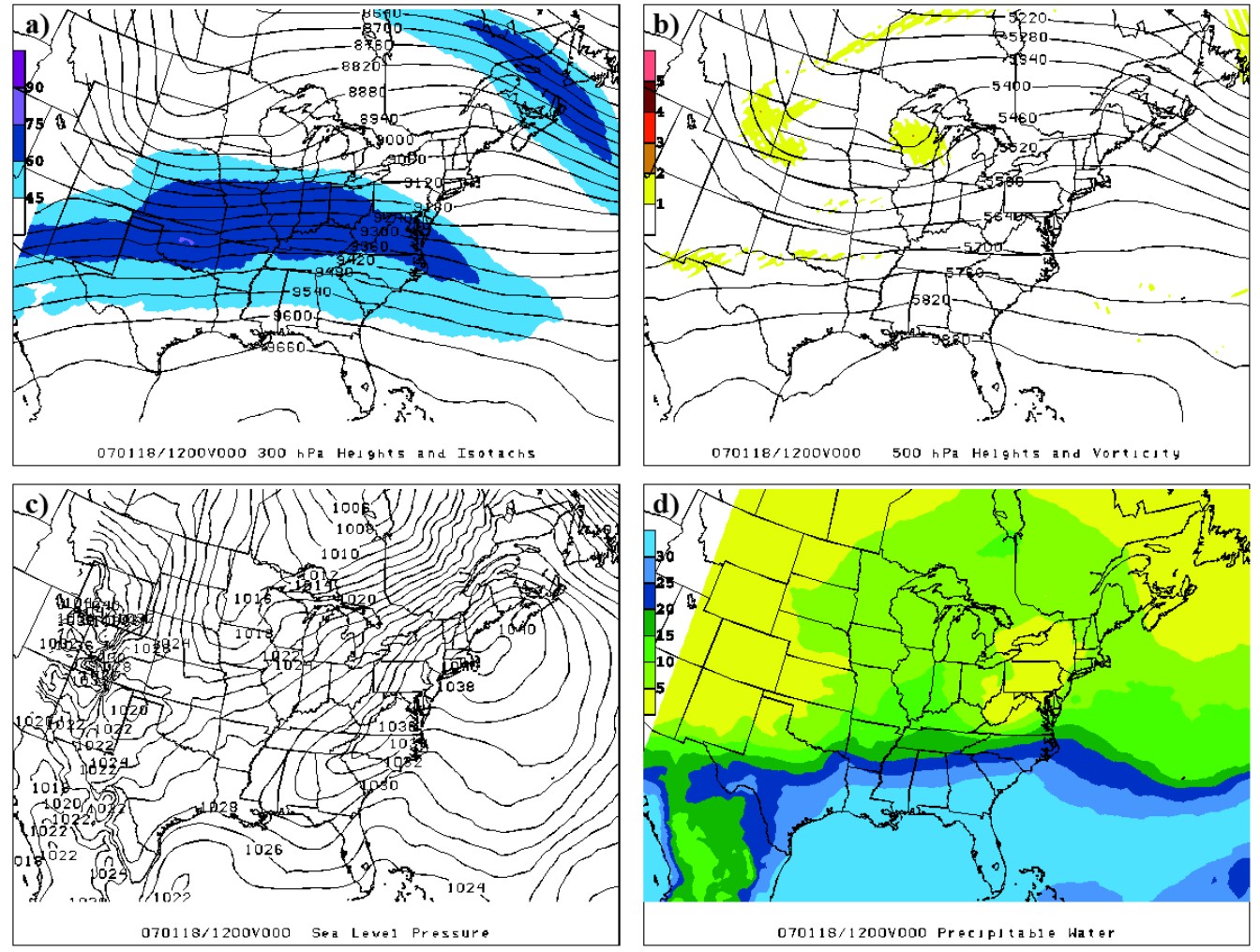

Figure 7. Same as in Fig. 6 except for 1200 UTC 18 January 2007. 


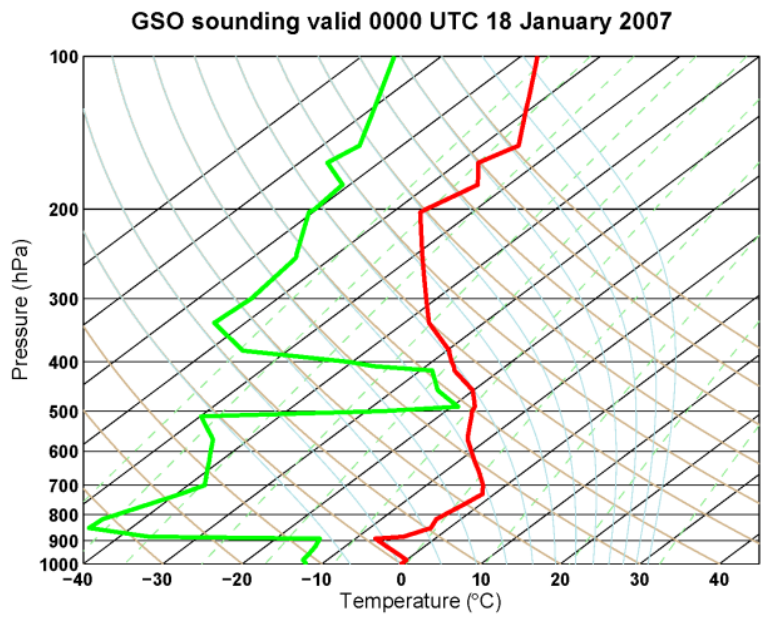

Figure 8. SkewT- $\log p$ plot from KGSO for 0000 UTC 18 January 2007. The red line is for temperature and the green line is for dewpoint.
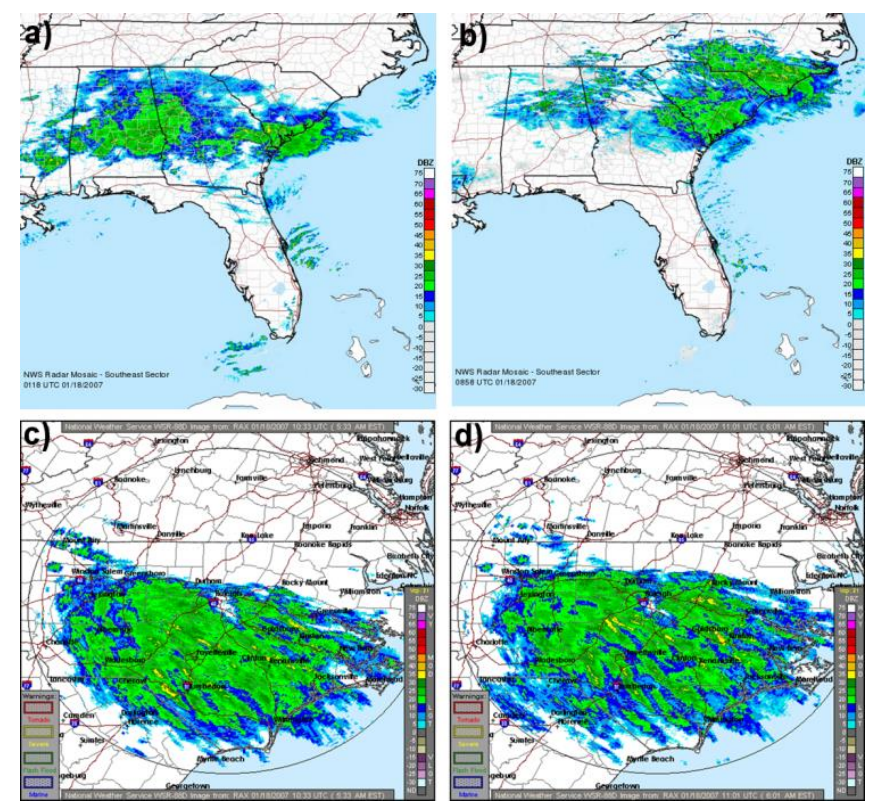

Figure 9. Panels (a) and (b) are regional mosaic base $\left(0.5^{\circ}\right)$ reflectivity at 0118 and 0859 UTC, respectively. Panels (c) and (d) are base $\left(0.5^{\circ}\right)$ reflectivity from the NWS Raleigh, NC, WSR-88D (KRAX) at 1033 and 1101 UTC, respectively.

9a). By 0900 UTC, the precipitation had spread across South Carolina and began to push northward into southern and central North Carolina (Fig. 9b).

Model forecasts showed significant lift in the 285$295 \mathrm{~K}$ isentropic layer with a confluent flow and saturation advancing northeast across southern North Carolina around 1200 UTC (not shown). The observed 1200 UTC sounding from KGSO confirmed this moistening in the 900-700-hPa layer while the boundary layer remained very dry with dewpoints near $-10^{\circ} \mathrm{C}$
(Fig. 10). The precipitation initially did not reach the ground as hydrometeors fell into the dry air, but at 1000 UTC a mix of light snow, sleet, and freezing rain was observed at KRDU (Table 2). A changeover to accumulating snow occurred (Table 2) as the higher reflectivities moved over the airport between 1030 and 1100 UTC (Figs. 9c-d). Light to moderate snow persisted for nearly $1.5 \mathrm{~h}$ before the intensity of the snow began to relax after 1230 UTC. The precipitation changed to a mix of sleet and snow by 1300 UTC. Low-level warm advection continued from just above the surface to $850 \mathrm{hPa}$ during the mid-morning (not shown), and precipitation reports promptly changed to freezing rain at KRDU by 1400 UTC and rain after 1800 UTC (Table 2).

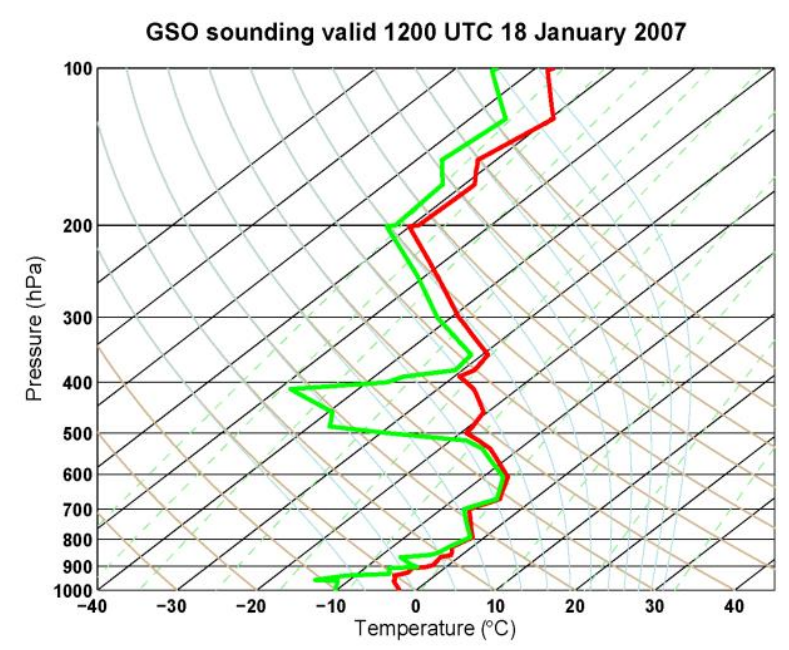

Figure 10. Same as Fig. 8, except for 1200 UTC 18 January 2007.

Hybrid CAD events such as this often are associated with evolving p-types as thermal advection, diabatic effects, and other processes compete. Even subtle changes in the vertical thermal profile can produce rapid p-type changes. The following sections will provide a description of the rapidly changing environment and resulting precipitation from AMDAR and MRR observations.

\section{a. Observations from AMDAR soundings}

Prior to the onset of precipitation, the 0000 UTC 18 January KGSO (Fig. 8) and KMHX (Fig. 11) radiosonde observations showed considerably dry boundary layer air, which was favorable for hybrid CAD development through evaporational cooling once precipitation began to fall. An AMDAR ascent sounding at 0102 UTC at KRDU showed a very similar tempera- 
Table 2. Meteorological Aerodrome Report (METAR) observations from KRDU, between 0600 and 2100 UTC 18 January 2007.

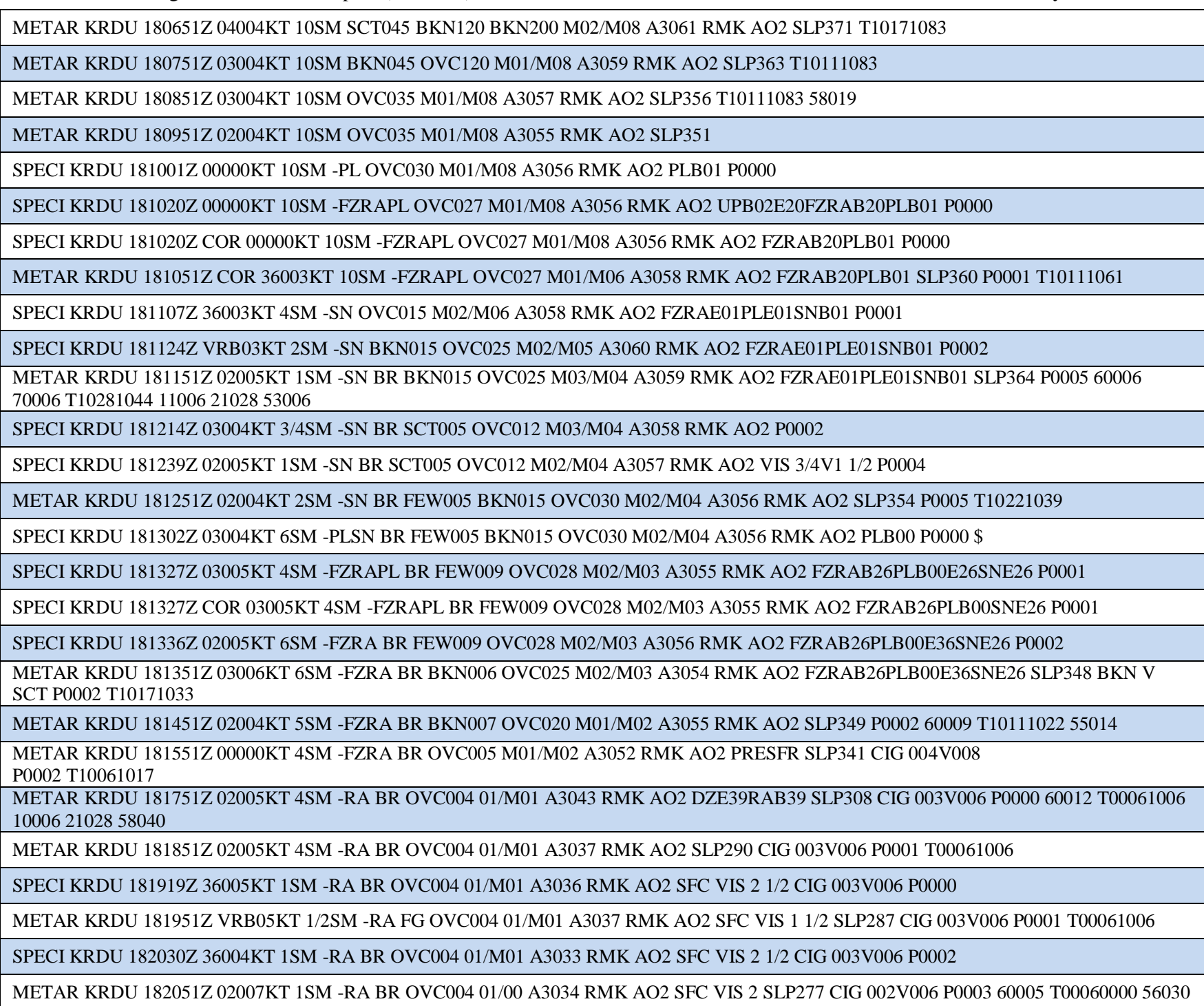

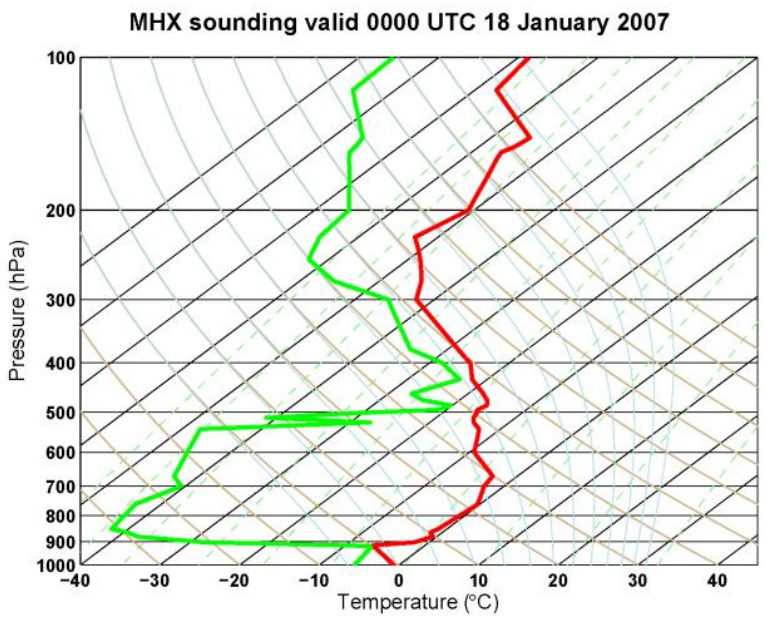

Figure 11. Same as Fig. 8 except for KMHX. ture profile (Fig. 12a), with a deep sub-freezing layer below $800 \mathrm{hPa}$ and the temperature at $850 \mathrm{hPa}$ around $-3^{\circ} \mathrm{C}$. By the next available KRDU AMDAR sounding at $0348 \mathrm{UTC}$, temperatures near $700 \mathrm{hPa}$ had cooled to around $-3^{\circ} \mathrm{C}$, while the $900-850-\mathrm{hPa}$ layer warmed to $-2^{\circ} \mathrm{C}$, setting up a nearly isothermal layer (Fig. 12b). A sounding during descent from 0903 UTC at KRDU, which was $\sim 1 \mathrm{~h}$ before the onset of precipitation, showed that temperatures aloft continued to cool, but strong warm advection between 925 and $900 \mathrm{hPa}$ created a warm nose of about $1{ }^{\circ} \mathrm{C}$ (Fig. 12c). Based on model projections, forecasters anticipated the brief development of this warm nose around $900 \mathrm{hPa}$ and then a slow reduction of the warm nose and cooling back to below $0^{\circ} \mathrm{C}$. The first report of precipitation at 

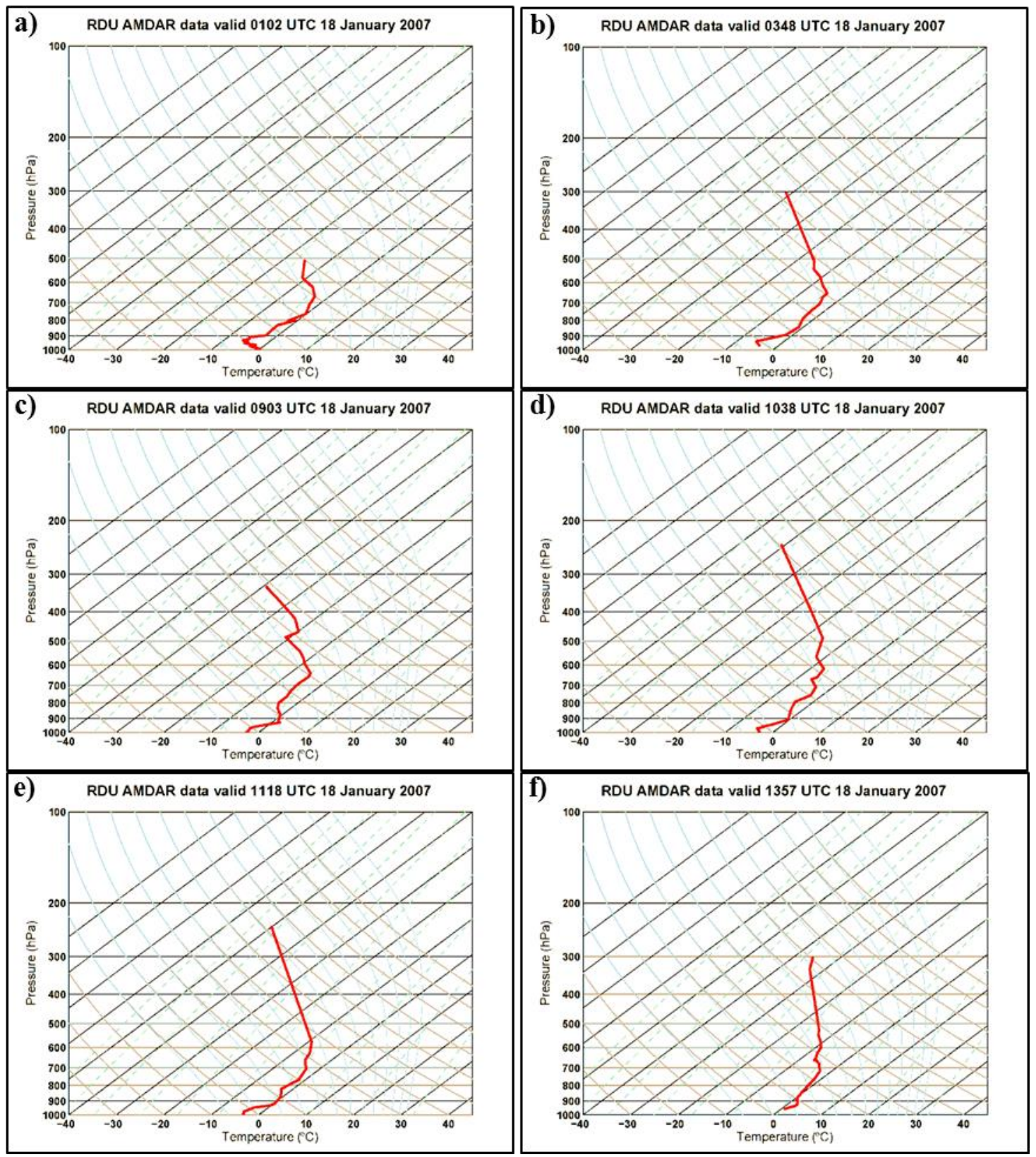

Figure 12. AMDAR soundings at KRDU (temperature only) for a) 0102 UTC, b) 0348 UTC, c) 0903 UTC, d) 1038 UTC, e) 1118 UTC, and f) 1357 UTC on 18 January 2007.

KRDU was light sleet and was observed at 1001 UTC (Table 2). During the next $30 \mathrm{~min}$, a mix of rain, freezing rain, and sleet was reported. The next AMDAR sounding at KRDU from 1038 UTC (Fig. 12d) revealed that the warm nose had been reduced significantly, much sooner than forecast by operational mesoscale models such as the RUC (Fig. 13), which was available to forecasters just prior to the official forecast issuance. This likely is due to diabatic contributions from cooling by the evaporation of hydrometeors initially, and then by the melting of snow. Later iterations of the RUC eventually showed the warm nose eroding, but forecasters were increasingly reliant on observations and less on model forecasts as the event unfolded. Shortly after 1100 UTC, all snow was reported at KRDU, and an AMDAR sounding at 1118 UTC showed a completely sub-freezing thermal profile (Fig. 12e). The snow lasted for $\sim 1.5 \mathrm{~h}$ with a light accumulation before changing back to freezing rain by 1330 UTC. A deeper and more significant warm layer 


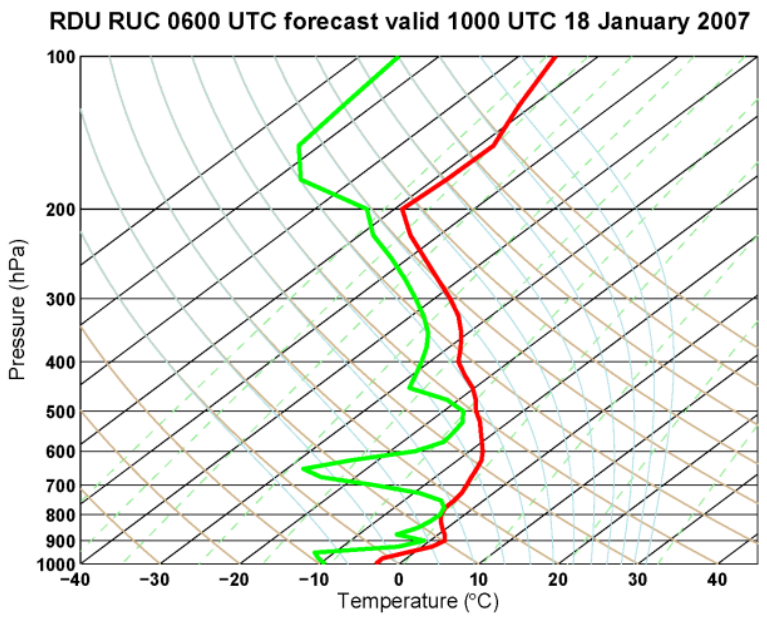

Figure 13. RUC 4-h forecast sounding from the 0600 UTC 18 February 2007 run for KRDU. The red line is for temperature and the green line is for dewpoint.

was forecast, specifically by the RUC, to redevelop as warm advection increased (not shown). An AMDAR sounding at KRDU from 1357 UTC (Fig. 12f) showed that warming through a significantly deep layer (900$700 \mathrm{hPa}$ ) occurred, and as a result the precipitation reverted back to a predominately liquid phase by 1600 UTC. Figure 14 summarizes this subtle evolution of the warm nose from the perspective of the AMDAR soundings.

\section{b. Observations from a vertically pointing micro rain radar}

MRR data (Fig. 15) reveal that the first time radar echoes were observed near the surface was just before 1000 UTC, which is coincident with the time of the first surface reports of precipitation (Table 2). Fall velocities increased dramatically below $1200 \mathrm{~m}$ by 1000 UTC, indicative of a melting layer. This also coincides with the arrival of a warm nose centered at $900 \mathrm{hPa}$, with temperatures warming above $0{ }^{\circ} \mathrm{C}$ at $875 \mathrm{hPa}$. During the next hour, with surface temperatures in the -3 to $-5^{\circ} \mathrm{C}$ range (Table 2), the precipitation fell as a mix of freezing rain and some sleet. As the precipitation intensified between 1030 and 1100 UTC, the warm nose began to erode, owing to the aforementioned diabatic contributions. Dynamic cooling associated with the large-scale vertical ascent also helped cool the layer, potentially mitigating the initial impact of warm advection.

With a near freezing isothermal layer established aloft and an area of somewhat heavier precipitation moving over KRDU, a changeover to accumulating

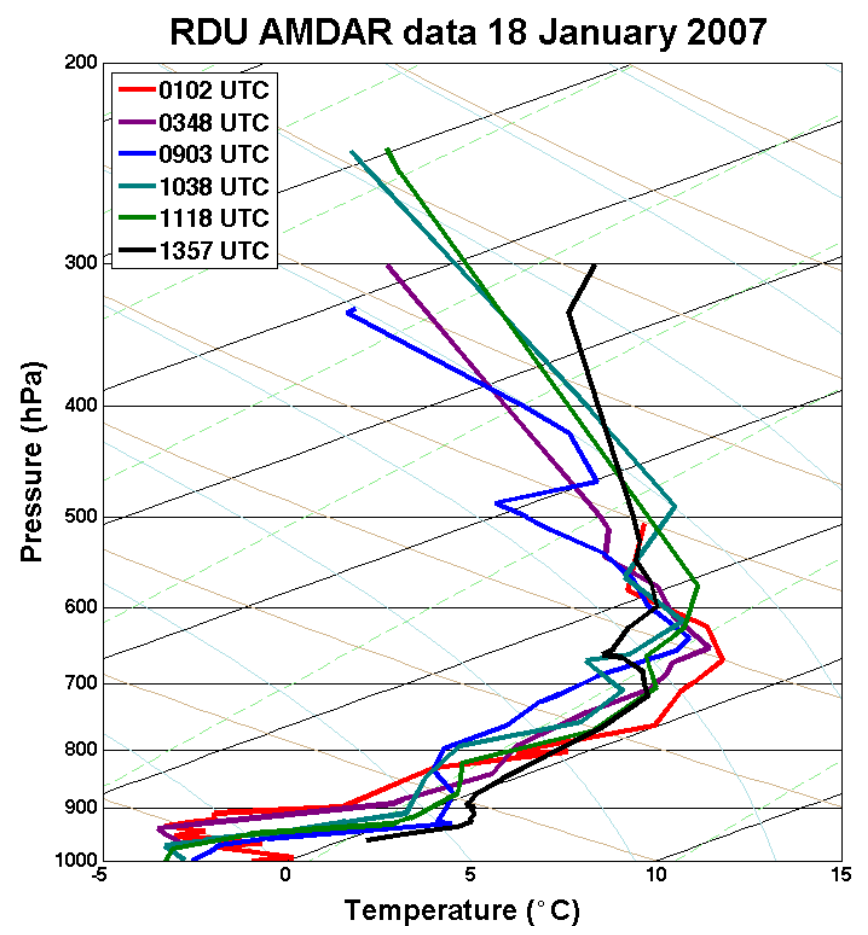

Figure 14. A summary plot of all KRDU AMDAR soundings between 0100 and 1400 UTC 18 January 2007. All lines are for temperature.

snow arrived between 1100 and 1300 UTC. MRR data show more uniform reflectivity around $900 \mathrm{~m}$, indicating the melting layer had been eroded (Fig. 15). A closer inspection (Fig. 16a) shows a slight left to right slant of the reflectivity values as they descended to the surface between 1100 and 1200 UTC, which indicates a slower fall velocity and suggests that the hydrometeors were snow. Doppler velocities at the same time decreased tremendously (Fig. 16b). The heaviest snow was reported at KRDU, slightly to the northwest of the radar, between 1214 and 1239 UTC when the visibility was $1.2 \mathrm{~km}(0.75 \mathrm{mi})$.

The MRR velocity imagery shown in the lower part of Fig. 15 reveals that fall velocities were relatively constant and low through about 1230 UTC. This image is consistent with snow or partially melted snow. Shortly after 1200 UTC, reflectivity values increased once again around $700 \mathrm{~m}$, likely resulting from the melting of snowflakes aloft that produces a coating of liquid water on the snowflakes and results in increased radar reflectivity (Fig. 17a). This signifies the redevelopment of a warm layer aloft and melting. Fall velocities show a slight increase, but not nearly as dramatic as the change in reflectivity values (Fig. 17b). The higher reflectivities did not extend completely to the surface, which suggests that the snow was melting 


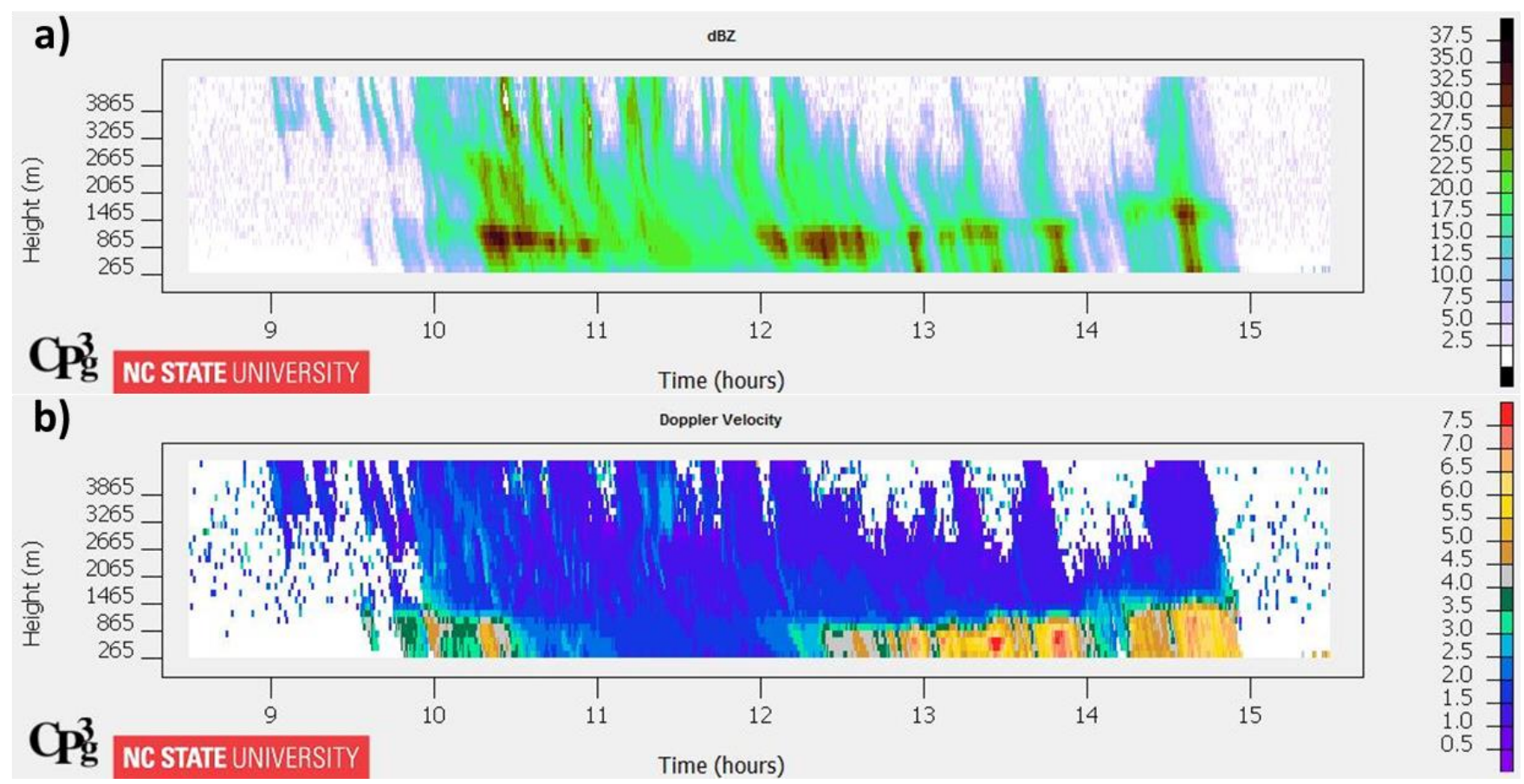

Figure 15. Time (UTC) versus height plots of a) reflectivity (dBZ) and b) Doppler velocity (m s${ }^{-1}$ ) for 0830-1530 UTC 18 January 2007.

aloft but was still reaching the surface as wet snow, or snow that partially melted and refroze. This provided forecasters with observational evidence that melting was developing, the warm layer was redeveloping, and a change in surface p-type was imminent. Just before 1300 UTC, the velocities increased further and the higher velocities extended to surface, as predominately sleet was observed (Table 2). Typically, sleet is a transitional precipitation type; during this event, sleet was observed with snow and freezing rain for $\sim 0.5 \mathrm{~h}$ between 1302 and 1336 UTC at KRDU. The precipitation transitioned to almost entirely freezing rain at 1336 UTC. As the warm nose became more pronounced and deeper, the above-freezing layer also grew higher, which is revealed in the rise of the melting layer height in the reflectivity and Doppler velocity data. Surface temperatures at this time still were $<0^{\circ} \mathrm{C}$, and the precipitation would accumulate as freezing rain until around 1600 UTC.

\section{Discussion}

During the winter event on 18 January 2007, nontraditional observations - such as soundings from commercial aircraft and MRR data-provided valuable information. Forecasters were anticipating a transition to all snow for a brief period when a warm nose was expected to erode. The enhanced vertical and tem- poral resolution of a MRR allowed forecasters to anticipate the onset of mixed precipitation and the quick changeover to all snow as reflectivity and Doppler velocity values decreased. Forecasters also were able to infer that the sloping descent of reflectivity values in time-height cross sections indicated the slow fall velocity of snowflakes. Several model runs leading up to the event had indicated that the warm nose would redevelop as warm advection continued, and the reappearance of a melting layer in MRR data only a few hours later provided confirmation that the atmosphere had begun to warm aloft. The warming would eventually lead to a change in p-type at the surface from snow to sleet and then to freezing rain. However, the arrival of the warm layer was delayed, compared to the forecast, which resulted in more snow than was initially forecast. With the snow beginning to accumulate readily during the morning commute in the Raleigh, North Carolina, area, there was potential for a reactionary amendment to the forecast by the oncoming day shift. The MRR was a critical tool used in the forecast process that morning as it provided observational evidence that the warming aloft was arriving. This information provided much needed confidence to the forecasters that the anticipated p-type change was forthcoming and that significant changes to the total snow accumulation forecast were unnecessary. Aircraft soundings also provided an additional valuable 


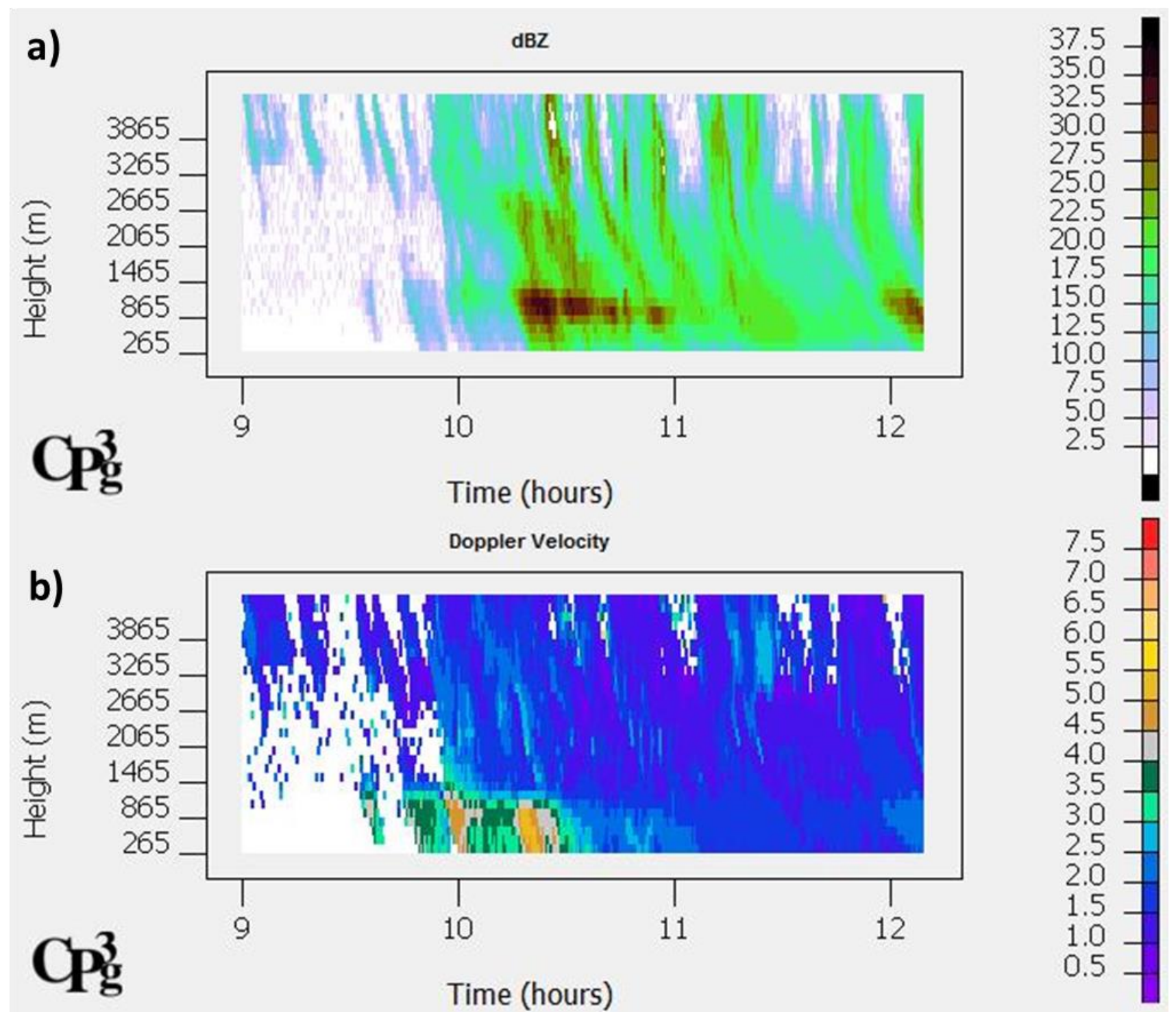

Figure 16. Same as Fig. 15, except for a small time period between 0900 and 1200 UTC.

dataset from which forecasters could gain insight into the evolution of the event. AMDAR soundings from KRDU and Charlotte/Douglas International Airport (KCLT, not shown) were available both spatially and temporally between the KGSO and KMHX radiosonde observations at 0000, 0600, and 1200 UTC. Whereas the MRR provided a nearly continuous stream of information about the precipitation over Raleigh, North Carolina, it only can observe changes in the precipitation characteristics (Doppler velocity and reflectivity). The ability to view the actual thermal profile from the AMDAR sounding provided complementary information and was of tremendous value. These soundings allowed the frequent assessment of the development, erosion, and then subsequent redevelopment of the warm nose that was responsible for the multiple changes in p-type.

The information gathered from the additional datasets then was used to issue a Special Weather Statement (SPS, Table 3), a NWS product often used to highlight high-impact weather, and in this case to provide greater detail regarding the anticipated changes in p-type.

After multiple SPSs were issued, and at the end of the forecast process associated with the morning update, the forecasters shared their reasoning in the Area Forecast Discussion (AFD, Table 4). The AFD specifically noted the use of the AMDAR soundings in 


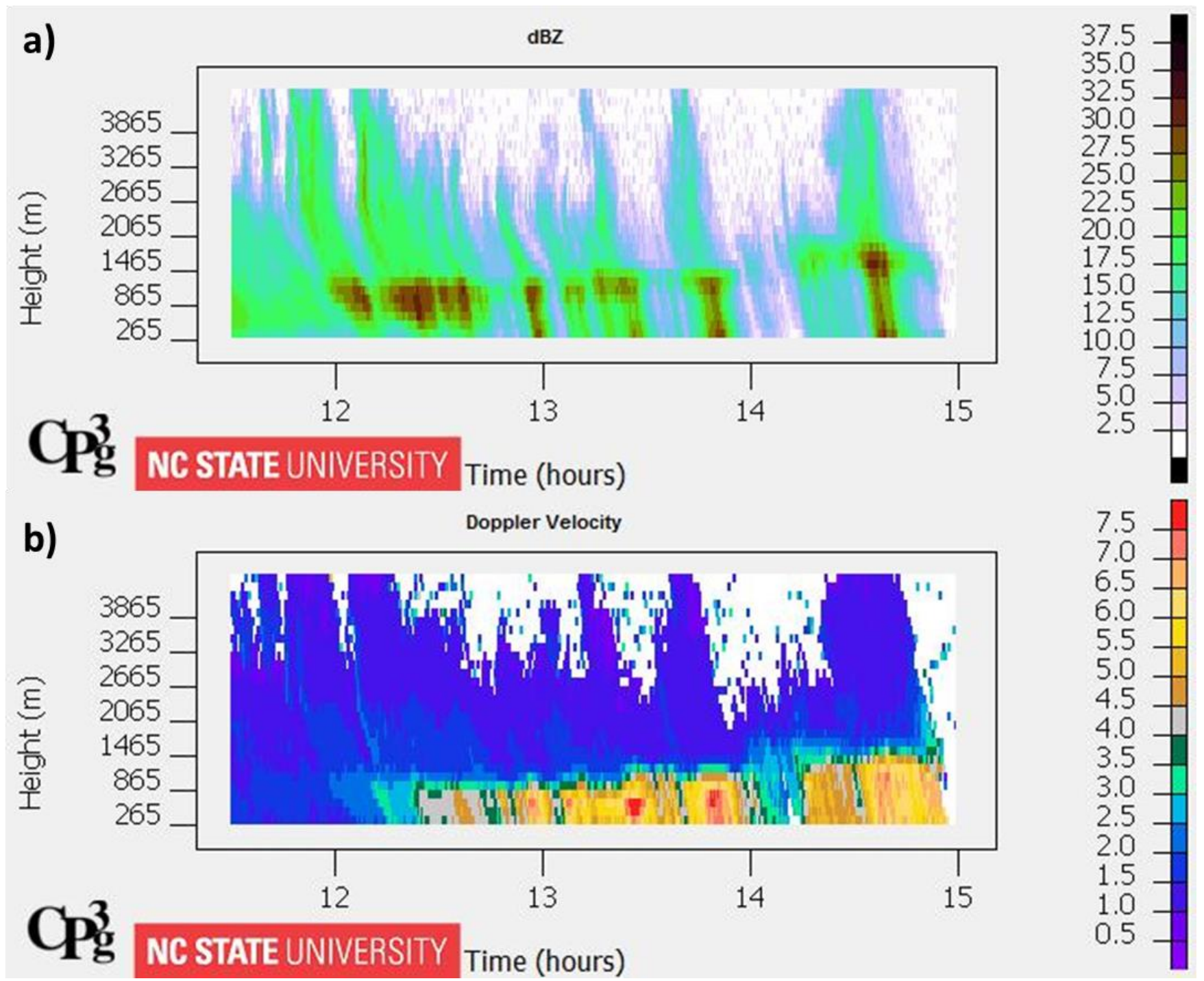

Figure 17. Same as Fig. 15, except for a small time period between 1130 and 1530 UTC.

the evaluation of the surge of warm air that was expected to change the snow to freezing rain in the Northwest Piedmont area near KGSO (Table 4).

\section{Conclusions}

This study (as well as other research) shows that forecasting winter p-type is a complex and difficult task, which can have significant impacts on the general public. Winter storms affecting central North Carolina frequently exhibit narrow and rapidly changing transitions among multiple p-types. The WSR-88D and traditional upper-air observations from routine soundings are an integral part of the weather watch, but owing to radar scan limitations and sounding frequency, their utility can be limited in the diagnosis and short-term forecasting of p-type changes. Although short-term model forecasts provide considerable value, computational expenses limit how quickly the forecasts are available, and model forecasts still have difficulty with boundary layer phenomena and can struggle with rapidly evolving systems. In this event, the additional knowledge of boundary layer temperatures and precipitation type allowed forecasters to see a four-dimensional transition that otherwise may have been missed by examining traditional observations, and it helped verify model forecasts. As a result, forecasters were able to provide updated forecasts based on a more accurate understanding of this transition.

High quality, frequently updated observational data are the foundation for accurate short-term fore- 
Table 3. SPS issued by NWSFO KRAH at 1122 UTC 18 January 2007. Italicized areas added for emphasis.

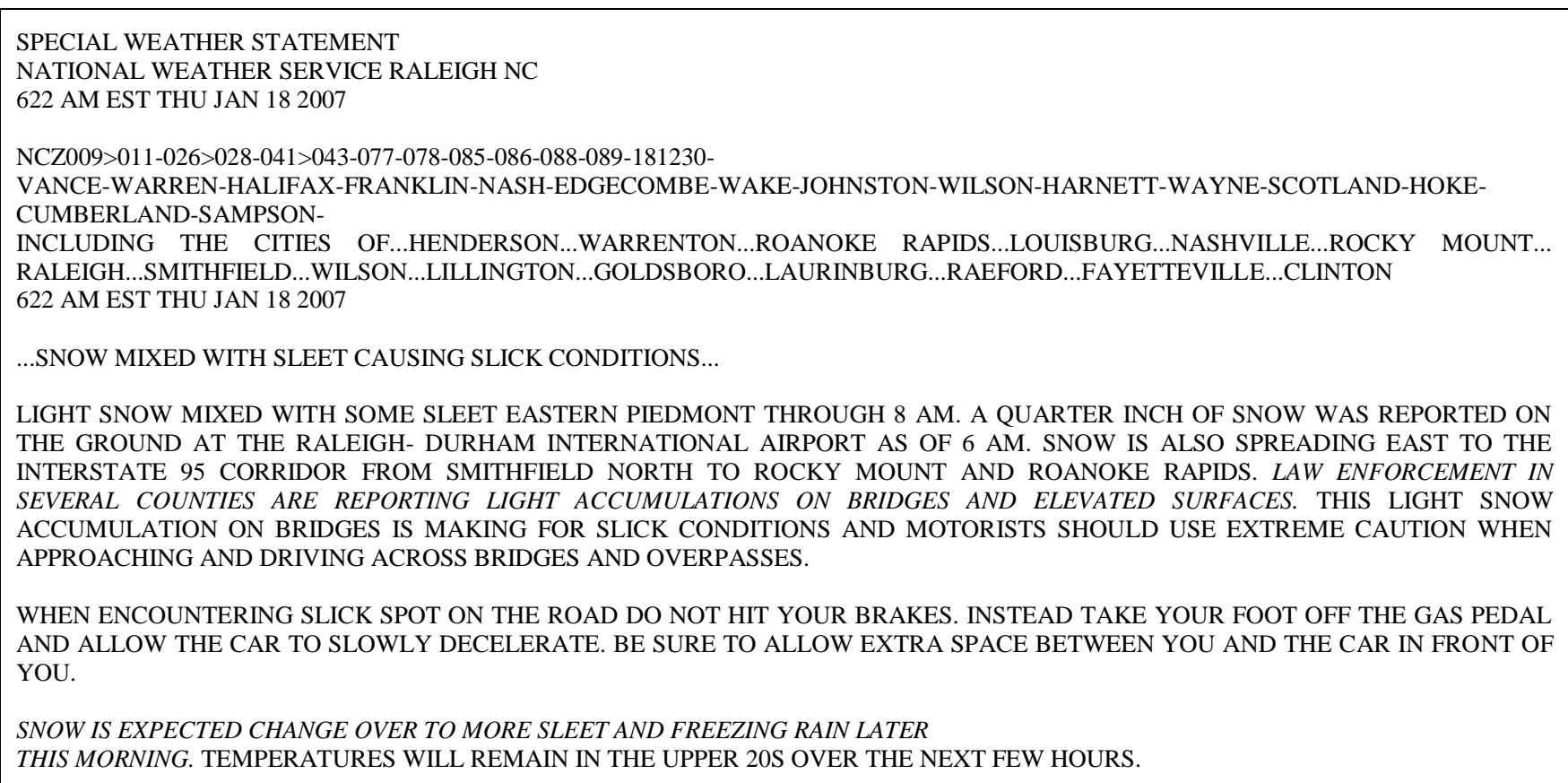

Table 4. AFD issued by NWSFO KRAH at 1533 UTC 18 January 2007. Italicized areas added for emphasis.

AREA FORECAST DISCUSSION

NATIONAL WEATHER SERVICE RALEIGH NC

1033 AM EST THU JAN 182007

.SHORT TERM /REST OF TODAY/...

$12 Z$ UPPER AIR ANALYSIS REVEALED TWO FEATURES THAT WILL PLAY MAJORROLES IN P-TYPE THIS AFTERNOON. FIRST, DRIER AIR NOTED UPSTREAM OF CENTRAL NC IN THE 700-500MB LAYER. THIS LAYER COINCIDES IN FAVORED DENDRITE REGION. WITH MOISTURE DECREASING...EXPECT SNOW TO DIMINISH NEXT FEW HOURS. ALSO NOTED WAS STRONG FETCH OF WARMER AIR AROUND 850MB UPSTREAM. THIS WARM AIR SURGE ALSO NOTED IN AIRCRAFT SOUNDINGS FROM CLT AND AREA VAD WIND PROFILES FROM ACROSS AREA. THUS EXPECT PATCHES OF SNOW OVER THE NW PIEDMONT TO TRANSITION TO FREEZING RAIN NEXT COUPLE HOURS WITH MAINLY LIGHT PRECIP EXPECTED THROUGH THE AFTERNOON. DO NOT EXPECT THE TRIAD REGION TO WARM TO AROUND FREEZING UNTIL LATE IN THE DAY. THE PERSISTENT FREEZING PRECIP WILL LIKELY RESULT IN ICE ACCUMULATION OF A TENTH OF AN INCH.

IN THE NE PIEDMONT...WIDESPREAD FREEZING RAIN WILL TRANSITION TO RAIN AS SURFACE TEMPS RISE TO AROUND FREEZING WITH MUCH WARMER AIR ALOFT. WILL MAINTAIN CATEGORICAL POPS FOR NOW. EXPECT PRECIP TO DIMINISH SWNE LATE TODAY AND EARLY TONIGHT. FINALLY...ADJUSTED MAX TEMPS DOWN A DEGREE OR TWO...MAINLY IN THE NORTHERN PIEDMONT...

casts. The additional information at higher temporal frequencies and smaller spatial scales supplements the information provided by the traditional network of observations and provides considerable value during high-impact weather events. More frequent and accurate visualizations of how the atmosphere is evolving allow forecasters to make more accurate, higher-confidence, critical forecasts. With increasing demand for more frequent updates to NWS gridded public forecasts and communication with media and emergency management, additional observations like the MRR and aircraft soundings are more vital than ever.

Acknowledgments. The authors thank Dr. Sandra Yuter of the North Carolina State University Cloud and Precipitation Processes and Patterns research group who provided real-time access to the MRR to NWSFO Raleigh. The authors also thank the anonymous reviewers and Brian Miretzky for providing suggestions that greatly improved this work. We acknowledge Keith Sherburn of North Carolina State University who greatly assisted in the acquisition of data and the production of the skew $T-\log p$ figures, as 
well as the NWSFO Raleigh forecasters who contributed to the event review. Finally, we appreciate the student volunteer, Russ Johnson, for the hourly analysis of AMDAR observations. Reference to any specific commercial products, process, or service by trade name, trademark, manufacturer, or otherwise does not constitute or imply its recommendation or favoring by the United States Government or NOAA/NWS. Use of information from this publication shall not be used for advertising or product endorsement purposes.

\section{REFERENCES}

Bailey, C. M., G. Hartfield, G. M. Lackmann, K. Keeter, and S. Sharp, 2003: An objective climatology, classification scheme, and assessment of sensible weather impacts for Appalachian cold-air damming. Wea. Forecasting, 18, 641-661, CrossRef.

Bell, G. D., and L. F. Bosart, 1988: Appalachian cold-air damming. Mon. Wea. Rev., 116, 137-161, CrossRef.

Benjamin, S. G. and Coauthors, 2004: An hourly assimilation-forecast cycle: The RUC. Mon. Wea. Rev., 132, 495-518, CrossRef.

Brennan, M. J., and G. M. Lackmann, 2005: The influence of incipient latent heat release on the precipitation distribution of the 24-25 January 2000 U.S. East Coast cyclone. Mon. Wea. Rev., 133, 1913-1937, CrossRef.

Crum, T. D., and R. L. Alberty, 1993: The WSR-88D and the WSR-88D Operational Support Facility. Bull. Amer. Meteor. Soc., 74, 1669-1687, CrossRef.

Daniel A. E., J. N. Chrisman, C. A. Ray, S. D. Smith, and M. W. Miller, 2014: New WSR-88D operational techniques: Responding to recent weather events. Preprints, 30th Conf. on Environmental Information Processing Technologies, Atlanta, GA, Amer. Meteor. Soc., 5.2. [Available online at ams.confex.com/ams/ 94Annual/webprogram/Paper241216.html.]

Gay, D. A., and R. E. Davis. 1993: Freezing rain and sleet climatology of the southeastern USA. Clim. Res., 3, 209-220, CrossRef.

Hux, J. D., P. C. Knappenberger, P. J. Michaels, P. J. Stenger, H. D. Cobb III, and M. P. Rusnak, 2001: Development of a discriminant analysis mixed precipitation (DAMP) forecast model for mid-Atlantic winter storms. Wea. Forecasting, 16, 248-259, CrossRef.

Kain, J. S., S. M. Goss, and M. E. Baldwin, 2000: The melting effect as a factor in precipitation-type forecasting. Wea. Forecasting, 15, 700-714, CrossRef.

Keeter, K. K., S. Businger, L. G. Lee, and J. S. Waldstreicher, 1995: Winter weather forecasting throughout the eastern United States. Part III: The effects of topography and the variability of winter weather in the Carolinas and Virginia. Wea. Forecasting, 10, 42-60, CrossRef.
Kocin, P. J., and L. W. Uccellini, Eds., 2004. Northeast Snowstorms Volume I: Overview. Meteor. Monogr., No 40, Amer. Meteor. Soc., 296 pp.

Kumjian, M. R., 2013: Principles and applications of dualpolarization weather radar. Part I: Description of the polarimetric radar variables. J. Operational Meteor., 1 (19), 226-242, CrossRef.

Lackmann, G. M., K. Keeter, L. G. Lee, and M. B. Ek, 2002: Model representation of freezing and melting precipitation: Implications for winter weather forecasting. Wea. Forecasting, 17, 1016-1033, CrossRef.

Maglaras, G. J., J. S. Waldstreicher, P. J. Kocin, A. F. Gigi, and R A. Marine, 1995: Winter weather forecasting throughout the eastern United States. Part I: An overview. Wea. Forecasting, 10, 5-20, CrossRef.

Martner, B. E., 1997: Vertical velocities in a thunderstorm gust front and outflow. J. Appl. Meteor., 36, 615-622, CrossRef.

, and F. M. Ralph, 1993: Breaking Kelvin-Helmholtz waves and cloud-top entrainment as revealed by $\mathrm{K}$ band Doppler radar. Preprints, Ninth Conf. on Atmospheric and Oceanic Waves and Stability, San Antonio, TX, Amer. Meteor. Soc., 141-144.

, S. E. Yuter, A. B. White, S. Y. Matrosov, D. E. Kingsmill, and F. M. Ralph, 2008: Raindrop size distributions and rain characteristics in California coastal rainfall for periods with and without a radar bright band. J. Hydrometeor., 9, 408-425, CrossRef.

Mesinger, F., and Coauthors, 2006: North American Regional Reanalysis. Bull. Amer. Meteor. Soc., 87, 343-360, CrossRef.

Moninger, W. R., R. D. Mamrosh, and P. M. Pauley, 2003: Automated meteorological reports from commercial aircraft. Bull. Amer. Meteor. Soc., 84, 203-216, CrossRef.

, S. G. Benjamin, B. A. Jamison, T. W. Schlatter, T. L. Smith, and E. J. Szoke, 2010: Evaluation of regional aircraft observations using TAMDAR. Wea. Forecasting, 25, 627-645, CrossRef.

Peters, G., B. Fischer, and T. Andersson, 2002: Rain observations with a vertically looking micro rain radar (MRR). Bor. Environ. Res., 7, 353-362.

H. Münster, M. Clemens, and A. Wagner, 2005: Profiles of raindrop size distributions as retrieved by microrain radars. J. Appl. Meteor., 44, 1930-1949, CrossRef.

Rauber, R. M., L. O. Grant, D. X. Feng, and J. B. Snider, 1986: The characteristics and distribution of cloud water over the mountains of northern Colorado during wintertime storms. Part I: Temporal variations. J. Climate Appl. Meteor., 25, 468-488, CrossRef.

Wang, W., and N. L. Seaman, 1997: A comparison study of convective parameterization schemes in a mesoscale model. Mon. Wea. Rev., 125, 252-278, CrossRef.

Yuter. S. E., and R. A. Houze Jr., 2003: Microphysical modes of precipitation growth determined by S-band 
vertically pointing radar in orographic precipitation during MAP. Quart. J. Roy. Meteor. Soc., 129, 455476, CrossRef.

, D. A. Stark, M. T. Bryant, B. A. Colle, L. B. Perry, J. Blaes, J. Wolfe, and G. Peters, 2008: Forecasting and characterization of mixed precipitation events using the MicroRainRadar. Preprints, Fifth European Conf. on
Radar in Meteorology and Hydrology, Helsinki, Finland. [Available online at www4.ncsu.edu/ seyuter/ pdfs/080505YuteretalERAD.pdf.]

Zhang, F., C. Snyder, and R. Rotunno, 2003: Effects of moist convection on mesoscale predictability. J. Atmos. Sci., 60, 1173-1185, CrossRef. 